\title{
LA CAPTURA DEL SERVIDOR PÚBLICO: REQUISITOS SUSTANCIALES Y HABEAS CORPUS
}

\author{
Carlos Arturo Gómez Pavajeau* \\ Francisco Javier Farfán Molina**
}

\begin{abstract}
Resumen: La captura del servidor público investigado en un proceso penal está sujeta a reglas especiales y diversas a las previstas para la captura de los particulares, por cuanto la privación de la libertad de un funcionario puede afectar la continuidad, celeridad y eficacia de la función pública, como un valor constitucional igualmente relevante. Por tal motivo, como regla general, la captura del servidor público debe estar precedida de la solicitud de suspensión por parte de la Fiscalía General de la Nación y para que proceda sin suspensión previa, el fiscal debe consignar en su providencia las razones y argumentos por los cuales no se afecta el normal funcionamiento
\end{abstract}

* Profesor Titular de Derecho Penal y Disciplinario de la Universidad Externado de Colombia. Cofundador y Consejero Académico del Instituto Colombiano de Derecho Disciplinario y de la Confederación Internacional de Derecho Disciplinario. Coordinador Académico de Barras de la Defensoría del Pueblo y Consultor de la Escuela Judicial “Rodrigo Lara Bonilla”. Correo-e: gomezpavajeau@ hotmail.com. Bogotá, Colombia.

** Ex Procurador Delegado ante la Sala Penal de la Corte Suprema de Justicia. Profesor de la Universidad Externado de Colombia. Abogado Consultor. Correo-e: ffarfanmolina@hotmail.com. Bogotá, Colombia. Fecha de recepción: 26 de enero de 2015. Fecha de modificación: 30 de marzo de 2015. Fecha de aprobación: 30 de julio de 2015. Para citar el artículo: Francisco JaVIER FARFán Molina, CARLOS Arturo Gómez PaVAJEAu (2015). "La captura del servidor público: requisitos sustanciales y habeas corpus", en Revista Derecho Penal y Criminología, Vol. 36, n. ${ }^{\circ} 100$, enero-junio de 2015. Bogotá: Universidad Externado de Colombia, pp. 125-154. DOI: http://dx.doi.org/10.18601/ 01210483. v36n 100.07 
de la administración pública. La ausencia de motivación de este aspecto esencial constituye una vía de hecho procedimental que torna procedente la acción de habeas corpus, como mecanismo efectivo de garantía de la libertad personal. De igual manera, procede el habeas corpus cuando la captura del servidor público la ordena un fiscal sin competencia funcional para adelantar la investigación, por configuración de una vía de hecho por defecto orgánico.

Palabras clave: Captura de servidor público; Suspensión previa; Privación ilegal de la libertad; Habeas corpus; Continuidad de la función pública; Principio pro homine; Recurso de reposición; Providencias de trámite; Motivación de las providencias; Garantías judiciales; Control de convencionalidad.

\title{
CAPTURE OF PUBLIC SERVANT. REQUIREMENTS AND SUBSTANTIAL HABEAS CORPUS
}

\begin{abstract}
The capture of the public servant in a criminal investigation is subject to special rules and different to those for the capture of individuals, since the imprisonment of an official can affect continuity, speed and efficiency of the civil service, an equally important constitutional value. Therefore, as a rule capturing the public servant must be preceded by a request for suspension by the prosecution, and to proceed without suspension, the prosecutor in his providence should motivate the reasons and arguments why not affects the normal functioning of public administration. The lack of motivation for this essential aspect, affords a fact that becomes appropriate procedural habeas corpus as an effective mechanism guarantees of personal freedom. Similarly appropriate habeas corpus when catching public server ordered by a prosecutor without functional competence to advance research, by setting a path made by organic defect.

Keywords: Capturing Public Servant; After Suspension; Illegal Deprivation of Liberty; Habeas corpus; Continuity of Public Service; Pro homine Principle; Administrative Appeal; Procedural Orders; Motivation Measures; Judicial Guarantees; Control of Compliance.
\end{abstract}

\section{INTRODUCCIÓN Y PLANTEAMIENTO DEL PROBLEMA}

La captura del servidor público investigado en un proceso penal no está sujeta a las mismas reglas previstas para la captura de los particulares, por cuanto la privación de la libertad de un funcionario puede afectar, además del derecho fundamental del justiciable a la libertad física, el normal funcionamiento de la administración pública, como un valor constitucional igualmente relevante (artículos 1, 2, 6, 88 y 209 de la Carta Política). 
Es por ello que el artículo 359 de la Ley 600 de 2000, dispone:

De los servidores públicos. Cuando se imponga medida de aseguramiento en contra de un servidor público, en la misma providencia se solicitará a la autoridad respectiva que proceda a suspenderlo en el ejercicio del cargo. Mientras se cumple la suspensión, se adoptarán las medidas necesarias para evitar que el sindicado eluda la acción de la justicia.

Si pasados cinco (5) días desde la fecha en que se solicite la suspensión, ésta no se hubiere producido, se dispondrá la captura del sindicado.

Igualmente se procederá para hacer efectiva la sentencia condenatoria.

No es necesario solicitar la suspensión del cargo cuando a juicio del funcionario judicial, la privación inmediata de la libertad no perturba la buena marcha de la administración.

Una interpretación literal, lógica, sistemática y teleológica del citado texto legal, que fue declarado exequible por la Corte Constitucional mediante la Sentencia C-774 de 2001, permite afirmar válidamente que un presupuesto de legalidad para la captura de un servidor público es la suspensión previa del mismo, pues ninguna conclusión distinta se infiere de la citada disposición, al señalar que la captura solo procede si pasados cinco (5) días desde que fue solicitada la suspensión por el funcionario judicial, el nominador no la ha ordenado.

En otros términos, el sentido del artículo 359 del C. de P.P. de 2000 no tiene un objetivo distinto que establecer como presupuesto de legalidad para la captura de servidores públicos la suspensión previa del mismo en el ejercicio del cargo, con el propósito de preservar intereses y valores constitucionales relevantes, tales como la continuidad y normal desarrollo de la función pública y, al mismo tiempo, la garantía judicial para el procesado, quien solo será capturado una vez su situación administrativa se haya dejado en suspenso mediante un acto administrativo.

Y es tan claro el sentido de la citada disposición, que la misma es enfática al señalar que mientras se produce la suspensión del servidor público cuya captura se ha ordenado, las autoridades solo podrán adoptar medidas de cautela para que el sindicado no pueda eludir la acción de la justica, es decir, medidas relacionadas con la vigilancia razonable de sus movimientos y controles encaminados a evitar que se oculte. Y solo si han transcurrido cinco (5) días sin que se haya dictado el acto administrativo de suspensión, estaría habilitada la Fiscalía para hacer efectiva la captura del funcionario, sin el cumplimiento del citado presupuesto.

Cabe precisar que en la Ley 906 de 2004 no se incluyó ningún texto similar al artículo 359 de la Ley 600, en el que se regule la captura del servidor público. No obs- 
tante, ante dicho vacío legislativo, debe necesariamente aplicarse el mayor estándar de garantía de la libertad, consagrado para este punto específico en la Ley 600 de 2000 y en la Ley 136 de 1994; por demás, ya es pacífica la jurisprudencia penal que propone la aplicación de normas del Código de Procedimiento Penal del año 2000 a eventos regidos por el Código de Procedimiento de 2004, en especial cuando se trata de vacíos legislativos, favorabilidad y aplicación de principios del proceso penal ${ }^{1}$.

La jurisprudencia de Sala Penal de la Corte Suprema de Justicia, en línea de interpretación reiterada y homogénea, ha señalado que la suspensión previa en el ejercicio del cargo constituye un presupuesto para la legalidad de la captura de un servidor público, con la única excepción de la captura de servidores públicos investigados por delitos de conocimiento de los jueces especializados, incluidos los alcaldes, en cuyo caso, para la suspensión por parte de los gobernadores es necesario, además, que la medida de aseguramiento haya quedado en firme, como lo señala el numeral 5. ${ }^{\circ}$ del artículo 105 de la Ley 136 de 1994.

Sobre el punto concreto señaló la Sala Penal de la Corte, en providencia del 14 de abril de 2010 (Rad.n. 33.918), con ponencia del Magistrado YeSID RAMíREZ BASTIDAS que

[...] Para la imposición de medida de aseguramiento a un servidor público ha de tenerse en cuenta que previo a su aplicación se debe solicitar la suspensión en el ejercicio del cargo, pero en todo caso pasados cinco días se puede disponer su aprehensión.

En el caso de los alcaldes la medida de aseguramiento solo podrá hacerse efectiva una vez la resolución que la impone adquiera ejecutoria (Ley 136 de 1994, artículo 105-2).

El régimen especial y excepcional se aplica a las personas que deben responder ante los fiscales delegados ante los jueces penales del circuito especializados, quienes investigan, califican y, en su caso, acusan a los responsables de los delitos señalados en el artículo $5^{\circ}$ Transitorio de la Ley 600 de 2000.

Los servidores públicos, como es el caso de los alcaldes municipales, que sean investigados por delitos de competencia de los jueces penales especializados, podrán ser capturados con el propósito de surtir la indagatoria y el fiscal está facultado para mantenerlos privados de la libertad aún sin

1 En este punto es pertinente remitir al fallo de la Sala de Casación Penal de la Corte Suprema de Justicia del 13 de abril de 2011, rad. n. 35,946, M.P. MARÍA DEL RosARIo GonZÁLEZ, en el cual esa corporación judicial avaló la aplicación de la figura de extinción de la acción penal por indemnización integral de perjuicios, regulada en la Ley 600 de 2000, a un caso tramitado bajo la Ley 906 de 2004, que no consagra dicho instituto. Consideró la Corte que el principio de favorabilidad de la ley penal respalda dicha aplicación. 
necesidad de solicitar la suspensión en el ejercicio del cargo. Ello es así porque existe norma especial posterior (artículo 10 Transitorio) de aplicación preferente respecto de normas generales y anteriores que también regulan este supuesto.

Ninguna relevancia ni trascendencia puede tener en los asuntos que son de competencia de los jueces especializados que el procesado sea servidor público, porque el legislador -atendiendo la especial gravedad de las conductas- ha señalado unas reglas especiales de carácter excepcional que posibilitan impartir órdenes de captura contra todos aquellos sujetos a quienes se les atribuye responsabilidad en hechos que constituyen los más graves delitos previstos en el ordenamiento jurídico nacional, y, si existe mérito y se cumplen las exigencias procesales, ordenar la medida de aseguramiento privativa de la libertad sin esperar trámites administrativos o decisiones que dependan de la voluntad de otras autoridades (resaltado fuera de texto).

De lo anterior se colige, sin discusión alguna, que de acuerdo con la posición de la Sala Penal de la Corte Suprema de Justicia, 1) la suspensión previa en el ejercicio del cargo, desde una perspectiva general, es un presupuesto de legalidad indispensable para la captura de un servidor público en ejercicio, y 2) la única excepción en la cual procede la captura sin suspensión previa es la relacionada con los servidores públicos que son investigados por delitos de competencia de los Jueces Penales del Circuito Especializado, en cuyo caso sí procede la captura del servidor público sin suspensión previa, por las razones que expone la Corte.

Pero, además, puede agregarse, de la aplicación restrictiva de la orden de captura sin suspensión no solo juega su carácter excepcional, sino también la naturaleza transitoria de la disposición que la faculta. Excepcionalidad y transitoriedad implican, sobre todo cuando se trata de afectación de derechos fundamentales, interpretaciones restrictivas de los recortes a las garantías; de lo contrario, así resulta evidente, se estaría haciendo analogía en perjuicio de la parte procesada, lo que también es contrario a los artículos 6 inciso $2 .^{\circ}$ y 13 del Código Penal.

\section{EL TRATAMIENTO Y LAS REGLAS PROCESALES APLICABLES A LA CAPTURA DEL SERVIDOR PÚBLICO SON DIFERENTES A LAS QUE REGULAN EL TEMA RESPECTO A LOS PARTICULARES}

La señalada distinción no solo se advierte en el artículo 359 de la Ley 600 de 2000, que, como ya se dijo, ordena la suspensión previa a la captura del servidor público, sino también en el texto del artículo 347 del mismo, donde se indica que el servidor público capturado en flagrancia será escuchado en indagatoria y luego dejado en libertad, tomando obviamente las medidas de cautela para que no eluda la administración de justicia. 
Dice el mencionado artículo 347:

Flagrancia del servidor público. Cuando un servidor público se encuentre en situación de flagrancia, se le recibirá inmediatamente indagatoria y si no fuere posible se citará para recibirla en fecha posterior.

Después de practicar cualquiera de las diligencias mencionadas en el inciso anterior, será puesto inmediatamente en libertad y se tomarán las medidas necesarias para evitar que eluda la acción de la justicia.

La mencionada norma procura, al igual que la que exige la suspensión previa del servidor público antes de su captura, conciliar los valores y principios constitucionales que se encuentran comprometidos en el tema concreto y, de manera especial, el interés público en la persecución penal de los delitos y el normal funcionamiento de la administración pública.

Así lo sostuvo la Corte Constitucional al declarar la exequilbilidad del artículo 347 de la Ley 600 de 2000, mediante la Sentencia C-296 de 2002, con ponencia del Magistrado MARco Gerardo Monroy CABra. En esa ocasión, como ratio decidendi, dijo la Corte que

[...] Al llevar a cabo la verificación anterior respecto de la disposición acusada, la Corte encuentra que el tratamiento especial que ella dispensa a los servidores públicos resulta razonable si se tiene en cuenta el fin que persigue, el cual es la continuidad, celeridad y eficacia de la función pública, que se logra mediante la libertad del servidor sorprendido en flagrancia. Esta finalidad constitucional es la legítima razón de ser de este tratamiento diferente, por cuanto la necesidad de proteger la labor que cumplen los servidores públicos, evitando su innecesaria interrupción, justifica establecer para quienes cumplen esas funciones la excepción que la norma acusada introduce en relación con el común de los casos. Excepción que en modo alguno puede ser vista como un privilegio personal del servidor, sino como una garantía de la efectividad en el cumplimiento de la función; es decir, la garantía no es personal, sino funcional.

Establecida la presencia de un fin constitucionalmente válido, la Corte encuentra que la restricción al derecho a la igualdad que permite conseguirlo no resulta desproporcionada. En efecto, la norma señala las consecuencias que se siguen de la flagrancia del servidor público, indicando que si bien será puesto en libertad, también "se tomarán las medidas necesarias para evitar que eluda la acción de la justicia”. Estas medidas obviamente no pueden ser de tal naturaleza que lleguen a afectar los derechos fundamentales del implicado, erigiéndose en aquellas de naturaleza policiva que cumplan con la finalidad señalada de asegurar su comparecencia al proceso. La presencia de estas me- 
didas, significa de cualquier manera un recorte de la libertad del funcionario en aras de asegurar la correcta administración de justicia, que descartan la absoluta desproporcionalidad de la restricción al derecho a la igualdad y de la garantía funcional concedida (resaltado fuera de texto).

\section{LA EXCEPCIÓN A LA SOLICITUD DE SUSPENSIÓN PREVIA EN LA CAPTURA DEL SERVIDOR PÚBLICO}

Conforme al artículo 359, inciso final de la Ley 600 de 2000, "no es necesario solicitar la suspensión del cargo cuando a juicio del funcionario judicial, la privación inmediata de la libertad no perturba la buena marcha de la administración”.

Dicho texto admite dos interpretaciones diversas: 1) la primera, se orientaría a establecer una facultad discrecional para el funcionario judicial, en el sentido de que puede considerar subjetivamente, y sin sustentar con argumentos en la providencia, que la privación de la libertad del servidor público, en el caso concreto, no perturba la normal marcha de la administración, y por ello no es necesaria la suspensión previa a la captura, y 2) la otra interpretación, que a diferencia de la anterior, se encuentra en sintonía con el sistema de valores, principios constitucionales y con los estándares internacionales que regulan el derecho fundamental a la libertad personal, se orienta a exigirle al funcionario judicial que ordena la captura, la carga probatoria y argumentativa de exponer razonadamente los fundamentos que así lo aconsejan en el referido asunto, es decir, que necesariamente debe demostrar con elementos de convicción y argumentos judiciales, que la captura no afecta la administración y que en consecuencia es posible obviar la suspensión en el cargo.

Frente a las dos interpretaciones posibles del asunto, hay que preferir desde luego la segunda, ya que resulta en mayor armonía y concordancia con la Constitución y el bloque de constitucionalidad, y conduce por tanto a preservar con mayor eficacia los derechos fundamentales a la libertad personal, presunción de inocencia y debido proceso.

Así, de manera contundente, se sustentó en la aclaración de voto que hizo el Magistrado EduARdo Cifuentes MuÑoz a la Sentencia C-192 de 1995, proferida por la Corte Constitucional, al señalar que "entre dos entendimientos posibles de una norma, prima el que proyecte con fuerza superior los principios constitucionales".

No puede ser menos: la libertad es un valor sin igual reclamado desde el Preámbulo mismo de la Carta Política, de allí que se aplique lo que ha dicho la jurisprudencia constitucional, según la cual las "normas que reconocen valores condicionan las demás normas, y tienen un contenido abstracto y abierto, es decir, están formula- 
das como cláusulas generales que determinan criterios interpretativos del resto del ordenamiento"2.

Incluso, cuando no es posible dilucidar la dicotomía, se dice por la jurisprudencia constitucional:

Esta Corporación no duda en señalar que en caso de que no pueda establecerse una armonización concreta de los principios constitucionales en conflicto, debe darse preferencia al derecho fundamental al debido proceso, pues la eficacia de la administración de justicia y la seguridad jurídica no pueden alcanzarse a riesgo de sacrificar los derechos fundamentales de las personas. La justicia está al servicio de esos derechos, por lo cual en estos casos no puede aplicarse mecánicamente el principio constitucional de prevalencia del interés general (CP art. $1 .^{\circ}$ ) sobre el particular, pues en tales eventos la norma constitucional relevante es aquella que dispone que el Estado reconoce la primacía de los derechos inalienables de la persona (CP art. . $^{\circ}$ ). Por ello, en caso de conflicto irresoluble entre derechos constitucionales tan fundamentales, como la vida, la libertad o el debido proceso, y la persecución de objetivos estatales de interés general, como los que se logran con una justicia más eficaz, en principio debe el juez constitucional dar prevalencia a los derechos de la persona, pues es la única forma de conferir un efecto interpretativo real a la Carta de derechos. Este criterio hermenéutico es necesario, pues no puede darse preferencia a los intereses de la mayoría y al bienestar colectivo siempre que entran en conflicto con un derecho constitucional de una persona, con el deleznable argumento de que el derecho individual es particular, y el interés general prima siempre sobre el particular. En efecto, conviene recordar que los derechos constitucionales son precisamente limitaciones al principio de mayoría y a las políticas destinadas a satisfacer el bienestar colectivo. Esto significa que, como lo reconoce la doctrina, los derechos fundamentales son verdaderas cartas de triunfo contra el bienestar colectivo pues "condicionar la validez de un derecho constitucional a los criterios de las mayorías es quitarle toda su eficacia específica puesto que, en una gran medida, los derechos constitucionales fundamentales son las promesas que formulan las mayorías a las minorías -y a esas minorías radicales que son las personas- de que su dignidad e igualdad serán siempre respetadas. Por ello debe entenderse que el respeto de esos derechos es un componente integrante del interés general, tal y como esta Corporación lo había señalado" (resaltado fuera de texto) Sentencia T-669 de $1996^{3}$.

2 Corte Constitucional, Sentencia C-1287 de 2001.

3 Corte Constitucional, Sentencia T-784 de 2000. 
Y ello es así, por cuanto el principio pro homine, que rige la interpretación en materia de privación de la libertad y habeas corpus, no permitiría una conclusión distinta.

Bajo tal forma de entendimiento, en cualquier evento, el fiscal debe motivar su providencia, revelando y apreciando las pruebas que le otorgan el sustento para concluir por qué no se afecta la buena marcha de la administración pública con la captura del servidor en el caso concreto, como requisito para obviar la solicitud de suspensión previa. Si no lo hace, debe necesariamente colegirse que el tema se rige por la norma general, según la cual la suspensión previa en el ejercicio del cargo es un presupuesto de legalidad para la captura del servidor público, so pena de que la captura sea ilegal y proceda, por tanto, la acción constitucional de habeas corpus.

El ideal de justicia material es "consustancial al Estado Social de Derecho que emerge de los principios, valores y derechos constitucionales"4. El principio de justicia material ha sido calificado como "un valor superior del orden constitucional" 5 y, por tanto, es deber del juez "hacer efectivo el principio de justicia material"6, lo que impone la idea según la cual "el juez del Estado Social de Derecho debe optar necesariamente por satisfacer las exigencias concretas de la justicia material" 7 .

Es posible que el principio de justicia material "entre en conflicto con otros principios como el de certeza, seguridad y objetividad jurídica, caso en el cual, si no se tratare de normas prohibitivas o de mandato, la ponderación jurídica impone su prevalencia; puesto que "el principio de justicia material podría prevalecer sobre cualquier consideración legal" ${ }^{8}$ y sobre criterios formales 9 .

El artículo 359 inciso $4 .^{\circ}$ de la Ley 600 de 2000 no establece, entonces, a favor del fiscal del caso, una facultad discrecional absoluta ni lo habilita para decidir en forma libérrima en qué casos solicita suspender al servidor público, y en qué otros ordena la captura sin suspensión previa, pues la norma es clara en el sentido de que la regla general es la suspensión previa a la captura, y la excepción es la captura del funcionario sin suspensión, cuando a juicio del fiscal así proceda, lo cual debe ser sustentado con argumentos serios y responsables fundados en pruebas, en tanto no se afecta la buena marcha de la administración pública.

En la hipótesis de que no se motive la providencia en punto a la no afectación de la buena marcha de la administración pública por la captura sin suspensión previa, el fiscal

4 Corte Constitucional, Sentencia T-053 de 1994. Reiterada por Sentencia T-084 de 1998.

5 Corte Constitucional, Sentencia C-004 de 2003.

6 Corte Constitucional, Sentencia C-199 de 2002.

7 Corte Constitucional, Sentencia T-597 de 1992.

8 Corte Constitucional, Sentencia T-058 de 1995.

9 Corte Constitucional, Sentencia T-339 de 1997. 
incurrirá en una vía de hecho por defecto procedimental ostensible, pues la ausencia de motivación de la facultad prevista en el artículo 359 numeral 4. ${ }^{\circ}$ del C. de P.P. de 2000 , conduce sin lugar a dudas a que la captura se haya ordenado en contravía de las normas procesales y obviamente en desmedro del derecho a la libertad personal.

Es que una interpretación distinta conduciría a la vulneración del principio de igualdad y debido proceso, pues si el fiscal no debe motivar este aspecto de la captura, podría actuar selectivamente y de manera sesgada, ordenando la suspensión previa a la captura de algunos funcionarios públicos y de otros no, sin que resulte posible controvertir tal aspecto, pues no se conocen las razones que lo llevaron a la formación de tal juicio.

\section{EL RECURSO DE REPOSICIÓN NO PROCEDE FRENTE A PROVIDENCIA QUE ORDENA ILEGALMENTE LA CAPTURA}

El ataque a tal tipo de decisiones no es asunto del debate interno del proceso, lo cual indica que por tal vía no se satisfacen los derechos conculcados; empero, según la jurisprudencia, tampoco procede contra tales ilegalidades el habeas corpus por cuanto no se ha agotado el control natural, juego de interpretaciones malabaristas que vacían de contenido los derechos fundamentales constitucionales e internacionales, sin que haya autoridad que en la práctica remedie dicha situación. Aquí subyace, de manera espantosa, una práctica negativa mediante la cual nadie asume sus responsabilidades, contrariando deberes constitucionales como los señalados en el artículo 2 de la Carta Política y el llamado "control de convencionalidad" de que da cuenta la Convención Americana sobre Derechos Humanos, como se verá más adelante.

\section{Planteamiento general}

Debe precisarse, además, que la providencia que resuelve la situación jurídica es una decisión interlocutoria, en cuanto a la medida de aseguramiento que impone (detención preventiva), y de sustanciación o trámite, en lo relacionado con la orden de captura que se ha proferido como consecuencia de aquella (numerales $2 .^{\circ}, 3 .^{\circ}$ y $4 .^{\circ}$ del artículo 169 de la Ley 600 de 2000 y 161 y 162 de la Ley 906 de 2004).

Conforme a tal perspectiva de análisis, lo que es objeto del recurso de reposición es la medida de aseguramiento de detención preventiva, en lo relacionado con los presupuestos y exigencias de la misma, mas no la captura, que se considera una decisión de trámite, motivo por el cual la legalidad de esta no puede ser controvertida mediante los recursos ordinarios sino por vía de la acción constitucional de habeas corpus.

No obstante, aun siendo una resolución de sustanciación o trámite, la captura debe estar sujeta a una motivación mínima en la totalidad de los aspectos que tengan in- 
cidencia sustancial, de conformidad con los principios rectores del procedimiento penal. Al respecto, señala el artículo 13 numeral 2. ' de la Ley 600 de 2000: "el funcionario judicial deberá motivar, incluso cuando se provea por decisión de sustanciación, las medidas que afecten derechos fundamentales de los sujetos procesales" (resaltado fuera de texto).

La jurisprudencia penal tiene dicho que, cuando exista un vacío legislativo en el Código de Procedimiento Penal de 2004, en especial si se trata de un tema de principios que no resulten incompatibles con el sistema acusatorio, se aplicará la Ley 600 de 2000[10].

Así también, de manera diáfana, se desprende del artículo 1. ${ }^{\circ}$ del Código General del Proceso, el cual autoriza la aplicación de sus normas a otros procesos cuando no exista regulación expresa, siendo de cardinal importancia dos principios rectores como el de interpretación y solución de vacíos legislativos, en los cuales se acude a otras normas, a normas análogas y, muy especialmente, a la teoría general del proceso y del Derecho constitucional:

Artículo 11. Interpretación de las normas procesales. Al interpretar la ley procesal el juez deberá tener en cuenta que el objeto de los procedimientos es la efectividad de los derechos reconocidos por la ley sustancial. Las dudas que surjan en la interpretación de las normas del presente código deberán aclararse mediante la aplicación de los principios constitucionales y generales del derecho procesal garantizando en todo caso el debido proceso, el derecho de defensa, la igualdad de las partes y los demás derechos constitucionales fundamentales. El juez se abstendrá de exigir y de cumplir formalidades innecesarias (resaltado fuera de texto).

Artículo 12. Vacíos y deficiencias del código. Cualquier vacío en las disposiciones del presente código se llenará con las normas que regulen casos análogos. A falta de estas, el juez determinará la forma de realizar los actos procesales con observancia de los principios constitucionales y los generales del derecho procesal, procurando hacer efectivo el derecho sustancial (resaltado fuera de texto).

Dicha norma rectora, que tiene carácter prevalente en el sistema (artículos 24 de la Ley 600 de 2000 y 26 de la Ley 906 de 2004), se desestima cuando el fiscal no motiva el juicio que le permite concluir que no se afecta el normal funcionamiento de la administración pública, como presupuesto para aplicar la facultad prevista en el artículo 359 numeral 4. ${ }^{\circ}$ ibídem.

10 Corte Suprema de Justicia, Sala de Casación Penal, decisiones de abril 4 de 2006, M.P. LombanA Trujillo, radicación n. ${ }^{\circ}$ 24.187; mayo 15 de 2008, M.P. Socha SAlamanCA, radicación n. 28.716 , y agosto 24 de 2009, M.P. Bustos Martínez, radicación n. 31.900. 
En tal sentido, es claro entonces que, en principio, la existencia del recurso de reposición no puede ser un argumento válido para declarar la improcedencia de un habeas corpus interpuesto por una captura ilegal cuando se resuelve la situación jurídica, ya que lo relativo a la captura no puede controvertirse mediante tal medio de impugnación, por tratarse de una decisión de trámite.

\section{La orden de captura como resolución de sustanciación}

Las decisiones de sustanciación son aquellas que "se limitan a disponer" un trámite procesal, en tanto no resuelven un "aspecto sustancial", que ya viene decidido por la resolución que resuelve la situación jurídica (numerales $2 .^{\circ}, 3 .{ }^{\circ}$ y 4. ${ }^{\circ}$ del artículo 169 de la Ley 600 de 2000); empero, muy a pesar de ser una decisión de sustanciación, en tanto afecta la libertad, y por supuesto un derecho fundamental, de conformidad con el principio rector de inciso 2. de su artículo 13 debe ser "motivado", toda vez que "la actuación procesal se desarrollará teniendo en cuenta el respeto a los derechos fundamentales de los sujetos procesales" (artículo 9) y haciendo prevalecer el derecho sustancial en tanto búsqueda de su efectividad (artículo 16), imperativos normativos que prevalecen sobre las demás normas y sirven para fijar su interpretación (artículos 24 del C. de P.P. de 2000, 26 de la Ley 906 de 2004, 4 y 228 de la Carta Política).

Solo así se garantiza el acceso efectivo a la administración de justicia en los términos del debido proceso como mandato constitucional y de rectoría legal (artículos 229 de la Carta Política y 10 de la Ley 600 de 2000), cuyo desconocimiento es una muestra de la infracción al deber de absoluta lealtad de los funcionarios judiciales (artículo 17 ibídem).

Sobre el Derecho constitucional fundamental de acceso a la administración de justicia, consagrado en el artículo 229 de la Carta Política, que viene precedido por la orden de darles prevalencia a los derechos sustanciales por encima de los ritualismos procesales insulsos -artículo 228-, ha dicho la jurisprudencia constitucional:

La administración de justicia es función pública y, en tal calidad, debe ser ejecutada con primacía del derecho sustancial, sin dilaciones injustificadas y a través de un funcionamiento desconcentrado y autónomo. Estas características cualifican la administración de justicia e impiden que la garantía de su acceso se vea limitada a una perspectiva formal y, en contrario, obligan a que las controversias sometidas al estudio de la jurisdicción obtengan una decisión de fondo que otorgue certidumbre sobre la titularidad y el ejercicio de los derechos objeto de litigio $^{11}$ (resaltado fuera de texto).

11 Corte Constitucional, Sentencia T-134 de 2004, M.P. JAIME CóRdobA TriviÑo. 
En efecto, si el funcionario judicial alega la inimpugnabilidad del auto de sustanciación, se estaría profiriendo una especie de decisión inhibitoria, que no resuelve nada o niega resolver, incluso si se propone nulidad de la orden y así no se procede a su declaratoria.

La Corte Constitucional ha elaborado, atendidas las necesidades de dar prioridad y prevalencia al Derecho sustancial, la teoría de las decisiones inhibitorias implícitas:

Se está ante dos formas de sentencia inhibitoria injustificada y, por ello, contraria a la Constitución. La primera, el fallo inhibitorio manifiesto, en que el juez expresamente decide no resolver de fondo lo pedido sin haber agotado todas las posibilidades conferidas por el ordenamiento jurídico aplicable, $y$, la segunda, el fallo inhibitorio implícito, caso en el cual el juez profiere una decisión que en apariencia es de fondo, pero que realmente no soluciona el conflicto jurídico planteado y deja en suspenso la titularidad, el ejercicio o la efectividad de los derechos y prerrogativas que fundaban las pretensiones elevadas ante la jurisdicción ${ }^{12}$ (resaltado fuera de texto).

Cuando no se toma una decisión sobre la petición de nulidad o con evasivas no se entra a decidir lo pertinente, configurándose aquí materialmente la llamada decisión inhibitoria implícita, forma de apariencia de justicia, pero conculcadora de los derechos fundamentales, en tanto su realización material y goce efectivo queda sometido a un limbo jurídico, se violan los derechos constitucionales ya mencionados.

En consecuencia, dice la jurisprudencia constitucional que

... el acceso a la administración de justicia implica, entonces, la posibilidad de que cualquier persona solicite a los jueces competentes la protección o el restablecimiento de los derechos que consagran la Constitución y la ley. Sin embargo, la función en comento no se entiende concluida con la simple solicitud o el planteamiento de las pretensiones procesales ante las respectivas instancias judiciales; por el contrario, el acceso a la administración de justicia debe ser efectivo, lo cual se logra cuando, dentro de determinadas circunstancias y con arreglo a la ley, el juez garantiza una igualdad a las partes, analiza las pruebas, llega a un libre convencimiento, aplica la Constitución y la ley y, si es el caso, proclama la vigencia y la realización de los derechos amenazados o vulnerados. Es dentro de este marco que la Corte Constitucional no ha vacilado en calificar al derecho a que hace alusión la norma que se revisa -que está contenido en los artículos 29 y 229 de la Carta Política- como uno de los derechos fundamentales susceptible de protección jurídica inmediata a través de mecanismos como la acción de tutela prevista en el artículo 86 superior.

12 Ídem. 
(...) el derecho fundamental de acceso a la justicia no se satisface si el juez deja de pronunciarse sobre el asunto sometido a su decisión, quedando éste imprejuzgado" (Sentencia T-231 de 1994. M.P. EdUARdo CifuENTES MuÑoz. Reiterada en la sentencia T-954 de 2006. M.P. RodRIGO EsCOBAR GIL), en tanto que consiste en permitirle a los particulares acudir al Estado, como único titular del monopolio de la administración de justicia, para resolver los conflictos particulares o la defensa del ordenamiento jurídico. Por consiguiente, la jurisprudencia constitucional (en este tema, pueden verse, entre muchas otras, las sentencias C-426 de 2002, C-1177 de 2005, C-1194 de 2005, C-1083 de 2005, T-030 de 2005, T-909 de 2006 y T-1222 de 2004) ha considerado que se viola el derecho de acceso a la administración de justicia y por esa razón puede ser protegido por vía de tutela cuando la ley, la reglamentación, los jueces o sus decisiones, entre otros casos: i) impidan que se profiera una decisión de fondo, ii) cuando establecen traban irrazonables para acudir a la justicia, iii) no observen los términos procesales sin justificación al respecto, iv) no existieran instrumentos procesales que le permitan a los afectados acudir al Estado para resolver sus conflictos y, v) autoricen conflictos indefinidos, esto es, cuando no respeten la cosa juzgada ni la definición última de un conflicto ${ }^{13}$ (resaltado fuera de texto).

Por demás, en variadas decisiones, la Fiscalía confunde lo discrecional con lo arbitrario, desconociendo de tajo el Estado de Derecho:

No debe confundirse lo arbitrario con lo discrecional. En lo arbitrario se expresa el capricho individual de quien ejerce el poder sin sujeción a la ley. El poder discrecional por el contrario, está sometido a normas inviolables como las reglas de derecho preexistentes en cabeza del órgano o funcionario competente para adoptar la decisión en cumplimiento de los deberes sociales del Estado y de los particulares, a fin de proteger la vida, honra y bienes de los asociados, así como sus derechos y libertades ${ }^{14}$ (resaltado fuera de texto).

Como no es posible el ataque por la vía del recurso de reposición, puesto que este solo procede contra resoluciones interlocutorias (artículos 176, 185 y 186 de la Ley 600 de 2000), la única vía posible cuando se ordena la captura del servidor público sin suspensión previa, es el habeas corpus, el cual se ha vaciado de contenido sustancial en la línea jurisprudencial de la Sala Penal de la Corte Suprema de Justica. Por demás, como las decisiones sobre libertad se ejecutan inmediatamente (artículo 188), dejar en manos de la corrección interna por la vía de la reposición el remedio al agravio, cuando tal recurso es apenas ilusorio o un espejismo si se tiene en cuenta que existe una tendencia del ser humano a "santificar su propia obra" como fenóme-

13 Corte Constitucional, Sentencia T-766 de 2008, M.P. MARco Gerardo Monroy Cabra.

14 Corte Constitucional, Sentencia C-031de 1995, M.P. Hernando Herrera Vergara. 
no psicológico, es tanto como rendirle un saludo vano a la bandera, en perjuicio del recurso efectivo de naturaleza convencional universal (literales a) y b) del numeral 3..$^{\circ}$ del artículo 2 del Pacto Internacional de Derechos Civiles y Políticos) y americano (numerales 1. ${ }^{\circ}$ y 2. ${ }^{\circ}$ del artículo 25 de la Convención Americana sobre Derechos Humanos), el que se impone por virtud de los artículos 4 y 93 de la Carta Política y 29 de la Convención Americana.

\section{LA ACCIÓN CONSTITUCIONAL DE HABEAS CORPUS}

\section{Marco conceptual}

El habeas corpus es un derecho fundamental y una acción pública que tutela la libertad personal cuando alguien es privado de la misma con violación de las garantías constitucionales o legales, o dicha privación de la libertad se prolonga ilícitamente.

Dicha acción, que no se suspende ni siquiera durante los estados de excepción, solo se puede invocar ante los jueces por una sola vez y para su evaluación se debe aplicar el principio pro homine, en virtud del cual se coloca a la persona humana como valor superior, procurando interpretar el Derecho y las circunstancias en el cual será aplicado, consultando la hermenéutica que mayor cobertura de protección ofrezca con respecto a las garantías de libertad personal.

Bajo la anterior perspectiva, cualquier actuación de los poderes públicos, incluidas las autoridades judiciales, que represente una afectación del derecho a la libertad física de los ciudadanos, como consecuencia de una determinación arbitraria, desmedida o desproporcionada, que conduzca a una privación ilegal de la libertad o a una prolongación indebida de la misma, es susceptible de ser conjurada mediante la acción constitucional de habeas corpus, a fin de lograr que los jueces restablezcan el derecho fundamental conculcado, a través de la respectiva orden de libertad.

Tal como lo ha señalado la Jurisprudencia de la Sala Penal de la Corte Suprema de Justicia (decisión del 14 de abril de 2010, Rad. n. 33.918 ), con ponencia del Magistrado Yesid RAMíREZ BASTIDAS,

[...] En la determinación de la naturaleza jurídica del hábeas corpus se ha dicho que es un derecho constitucional fundamental (art. 30 de la Const. Pol.) de aplicación inmediata (art. 85, ibídem $)^{15}$ no susceptible de limitación durante los estados de excepción (arts. 93 y 214-2 ídem y art. $4^{\circ}$ de la Ley Estatutaria 137 de 1994), que se debe interpretar de conformidad con los tratados internacionales sobre derechos humanos ratificados por Colombia (art.

15 Corte Constitucional, Sentencia C-620 de 2001. 
93 de la Const. Pol. $)^{16}$ cuya regulación debe ser objeto de una ley estatutaria (art. 152-a, ibídem $)^{17}$, y también es un mecanismo procesal de protección de la libertad personal por cuanto es una acción pública constitucional que trata de hacer efectivo el derecho fundamental de libertad individual y, por lo tanto, se constituye en una garantía procesal ${ }^{18}$, según lo consagra el artículo primero de la Ley 1095 de 2006, Estatutaria del Hábeas Corpus.

La referida ley estatutaria establece en su artículo 1. ${ }^{\circ}$ que el hábeas corpus tutela la libertad personal cuando alguien es privado de ella (i) con violación de las garantías constitucionales o legales o (ii) ésta se prolonga ilegalmente. También procede la garantía de la libertad cuando se presenta alguno de los siguientes eventos ${ }^{19}$ :

(1) siempre que la vulneración de la libertad se produzca por orden arbitraria de autoridad no judicial; (2) mientras la persona se encuentre ilegalmente privada de la libertad por vencimiento de los términos legales respectivos; (3) cuando, pese a existir una providencia judicial que ampara la limitación del derecho a la libertad personal, la solicitud de hábeas corpus se formuló durante el período de prolongación ilegal de la libertad, es decir, antes de proferida la decisión judicial; (4) si la providencia que ordena la detención es una auténtica vía de hecho judicial.

La Constitución de 1991, en un claro avance en relación con la Carta Política anterior, estableció en su artículo 28 una reserva legal y judicial para la privación de la libertad, tomando en cuenta que el derecho fundamental de la libertad personal es el presupuesto de todas las demás libertades y derechos. Por ello, el constituyente (artículo 30) quiso darle una especial protección ante las actuaciones ilegales de las autoridades, mucho más expedita que la de los demás derechos fundamentales.

Ya se ha dicho por la doctrina y la jurisprudencia que entre otras características la acción de hábeas corpus tiene la de ser principal ${ }^{20}$, particularidad que la diferencia frente a la acción de tutela que sí fue diseñada como subsidiaria y solo procedente a falta de otro medio de protección más efectivo, particularidad en un todo acorde con los postulados de una sociedad que en la

16 Corte Constitucional, Sentencia C-496 de 1994.

17 Corte Constitucional, sentencias C-301 de 1993 y C-620 de 2001.

18 Corte Constitucional, Sentencia C-557 de 1992, salvamento de voto de los Magistrados ANGARITA Barón y Martínez Caballero.

19 Corte Constitucional, Sentencia C-260 de 1999.

20 Corte Suprema de Justicia, Sala de Casación Penal, autos de 26 de junio de 2008, radicación 30066, 10 de julio de 2008, radicación 30156 y 4 de septiembre de 2009, radicación 32572. 
interpretación de los derechos fundamentales privilegia el principio in dubio pro libertate (presunción general a favor de la libertad, propia de todo Estado social de derecho), que para potenciar su eficacia tiende a ampliarse con el postulado favor libertatis, que conduce no solo a que en supuestos dudosos se opte por la interpretación que mejor proteja los derechos fundamentales, sino que implica concebir el proceso hermenéutico constitucional como una labor tendente a maximizar y optimizar la fuerza expansiva y la eficacia de los derechos fundamentales en su conjunto ${ }^{21}$.

De lo anterior se sigue que el hábeas corpus está previsto para que se proteja la libertad en los siguientes supuestos:

- Por privación ilícita de la libertad. Se refiere a todos aquellos casos en que se violan las garantías constitucionales y legales al privar a una persona de la libertad.

- Por prolongación ilícita de la privación de la libertad. Esto ocurre cuando a una persona se la ha privado legalmente de la libertad pero la limitación del derecho se prolonga más allá de lo permitido constitucional y legalmente.

- Por configuración de una auténtica vía de hecho judicial en la providencia que ordena la privación de la libertad o en decisiones posteriores que impiden el acceso a la misma ${ }^{22}$, como podría ser el caso de una medida de aseguramiento privativa de la libertad sin motivación suficiente o respecto de un delito que no acarrea prisión.

Bajo tal forma de entendimiento, la captura de un servidor público sin que se produzca previamente la suspensión en el cargo que viene ejerciendo, vulnera las garantías constitucionales y legales del procesado, afecta los intereses estatales relacionados con el normal funcionamiento de la administración pública y es contraria a las reglas procesales que disponen, con carácter imperativo, que antes de la captura del servidor público se produzca su suspensión, lo que torna viable la interposición de la acción de habeas corpus, como único mecanismo idóneo para evitar que la vulneración del derecho fundamental a la libertad personal se prolongue en el tiempo.

21 Antonio Enrique Pérez Luño, Derechos humanos, Estado de Derecho y Constitución, Madrid, Editorial Tecnos, 1991, pp. 315 y 316.

22 Esta línea argumentativa aparece en la jurisprudencia de la Corte Suprema de Justicia, Sala de Casación Penal, con el auto de 2 de mayo de 2007, radicación 27.417, y ha sido reiterada sucesivamente en las decisiones de 10 de julio de 2008, radicación 30156; 7 de noviembre de 2008, radicación 30.772; 16 de enero de 2009, radicación 31.066; 21 de abril de 2009, radicación 31.673 y 4 de septiembre de 2009 , radicación 32.572 , entre otras. 


\section{El principio pro homine}

Conforme al artículo 1. ${ }^{\circ}$ de la Ley 1095 de 2006, para decidir la acción de habeas corpus se aplicará el principio pro homine.

El pro homine es un principio interpretativo del Derecho internacional de los Derechos Humanos, que debe ser utilizado por los tribunales locales, y que permite aplicar la solución normativa y la interpretación más favorable a los intereses de la persona sometida al ius puniendi, en punto de su libertad física, por ejemplo.

Conviene advertir que los principios jurídicos, como el pro homine, fijan orientaciones especiales para la determinación del contenido del Derecho; ayudan a interpretar con mayor precisión los preceptos legales; los complementan, integran, optimizan la vida normativa buscando el mejor alcance de la norma. Así entonces, no puede caber duda de que la aplicación del principio pro homine o pro libertate debe ser el punto de partida para una adecuada interpretación de los derechos fundamentales garantizados por la Constitución Nacional.

En este sentido, el principio pro hominis prescribe cuáles deben ser, en primer lugar, la plataforma de acción para interpretar los derechos fundamentales; en segundo lugar, el sentido protectorio que debe adjudicársele a la interpretación en favor del más débil; en tercer lugar, dar certidumbre sobre los límites de los derechos fundamentales, y en cuarto lugar, cómo debe dirimirse una decisión jurisdiccional entre diversas soluciones posibles, debiendo optar por la solución más beneficiosa a los derechos del individuo, soslayando aquella que garantice en menor grado un derecho fundamental. Por tal motivo, todo desconocimiento jurisdiccional de estos estándares importa una flagrante interpretación violatoria de tal principio, el que constituye un valor de Garantía de Interpretación de la Constitución.

En suma, se trata entonces de "un criterio hermenéutico que informa todo el Derecho de los Derechos Humanos, en virtud del cual se debe acudir a la norma más amplia o a la interpretación más extensiva, cuando se trata de reconocer derechos protegidos o, inversamente, a la norma o a la interpretación más restringida cuando se trata de establecer restricciones permanentes al ejercicio de los derechos o a su suspensión extraordinaria

Trasladadas estas premisas al estudio concreto, se evidencia que la interpretación según la cual la suspensión previa en el ejercicio del cargo es condición de legalidad para la captura de un servidor público debe ser asunto indiscutido, y si el fiscal estima que la suspensión no es necesaria por cuanto no se afecta el normal funcionamiento de la administración pública, así debe sustentarlo en las motivaciones de su providencia, lo cual no solo está en armonía con la jurisprudencia de la Corte Constitucional y de la Corte Suprema de Justicia sobre el punto, tal como se explicó anteriormente, sino con el principio pro homine, pues se esfuerza por diseñar una tesis que amplifica y 
potencia los derechos fundamentales de las personas que se encuentran en riesgo de ser privadas de la libertad mediante captura ilegal, interpretando de la manera más restrictiva posible las posibilidades del fiscal para eludir la suspensión que resulta indispensable, como requisito de legalidad, antes de proceder a la captura de un servidor público.

\section{LA JURISPRUDENCIA DE LA SALA PENAL DE LA CORTE SOBRE HABEAS CORPUS Y LA INTERPRETACIÓN RESTRICTIVA QUE CONDUCE A LA INEFICACIA PRÁCTICA DE DICHA ACCIÓN CONSTITUCIONAL PARA GARANTIZAR LA LIBERTAD PERSONAL}

La Jurisprudencia de la Corte, de manera reiterada y automática, y sin proceder al análisis particular de cada caso concreto, ha señalado e insistido en el carácter residual y subsidiario de la acción de habeas corpus, en virtud de lo cual, ante la existencia de otra vía de impugnación frente al acto ilegal de captura, la acción constitucional se torna improcedente, ya que dicha acción no está llamada a sustituir el trámite del proceso penal ordinario ${ }^{23}$.

Ha señalado la Corte, por ejemplo, que

... cuando existe un proceso penal en trámite, no puede utilizarse el habeas corpus con ninguna de las siguientes finalidades: 1 . sustituir los procedimientos judiciales comunes dentro de los cuales deben formularse las peticiones de libertad. 2. Reemplazar los recursos ordinarios de reposición y apelación establecidos como mecanismos legales idóneos para impugnar las decisiones que interfieran el derecho a la libertad personal. 3. Desplazar al funcionario judicial competente y 4 . Obtener una opinión diversa -a manera de instancia adicional- de la autoridad llamada a resolver lo atinente a la libertad de las personas.

Por tanto, a partir del momento en que se impone la medida de aseguramiento, todas las peticiones que tengan relación con la libertad del procesado deben elevarse al interior del proceso penal, y no a través del mecanismo constitucional del habeas corpus, pues se reitera, esta acción no está llamada a sustituir el trámite del proceso penal ordinario ${ }^{24}$.

23 Corte Suprema de Justicia, Sala de Casación Penal, auto del 29 de agosto de 2007, rad 28.241; auto de 25 de enero de 2007, rad. 26.810, M.P. JAVIER ZAPATA; auto de 23 de octubre de 2007, rad. 28.598; providencia de 3 de febrero de 2010, rad. 33.483, M.P. MARÍA DEL RosARIo GoNZÁLEZ, y providencia del 25 de mayo de 2010, rad. 34.246, M.P. SigIFREDo ESPINOSA.

24 Corte Suprema de Justicia. Sala de Casación Penal, autos del 26 de junio y 25 de agosto de 2008. Rads n. 30.066 y 30438. 
Tal premisa, que se estima correcta desde una perspectiva general, ha sido sin embargo extendida hasta confines que han tornado inane la acción de habeas corpus, pues incluso en casos en los que la decisión judicial de captura constituye una vía de hecho, el juez constitucional acude a la cláusula de subsidiariedad para declarar, sin más ni más, la improcedencia de la acción.

En otros eventos, cuando el recurso ordinario que existe no procede porque la captura, como antes se indicó, es una decisión de sustanciación o trámite, los jueces constitucionales echan mano de manera torticera y facilista a la referida jurisprudencia de la Sala Penal, para indicar también, de forma inadmisible, que sobre la improcedencia del recurso ordinario debe pronunciarse es el mismo fiscal cuya arbitrariedad se acusa.

Así mismo, en procesos contra aforados, es decir, de única instancia, y cuyas condiciones particulares muestran que el recurso ordinario no será como regla general un mecanismo idóneo para la protección y restablecimiento del derecho fundamental vulnerado con la captura ilegal, se viene aplicando también la citada regla jurisprudencial, con lo cual, en la práctica se ha desvirtuado la voluntad del constituyente, en el sentido de consagrar el habeas corpus como un mecanismo eficaz para la protección de la libertad física.

\section{LA IMPROCEDENCIA DEL HABEAS CORPUS DEBE EVALUARSE EN CADA CASO CONCRETO CONSULTANDO LAS CARACTERÍSTICAS PARTICULARES DEL MISMO, ESPECIALMENTE EN LO RELATIVO AL ACCESO A LA JUSTICIA Y EFECTIVIDAD DEL MEDIO DE DEFENSA ALTERNATIVO, CONFORME A CRITERIOS DE CONTROL DE CONVENCIONALIDAD}

Tal criterio, que compartimos plenamente, lo ha desarrollado la plausible jurisprudencia de la Sala Penal del Tribunal Superior de Bogotá, en procura de lograr la prevalencia del derecho a la libertad amenazado y vulnerado por decisiones de única instancia que constituyen vías de hecho y frente a las cuales el único recurso efectivo del ciudadano es acudir a la acción de habeas corpus.

Sobre el tema aseveró el citado Tribunal, en decisión del 17 de mayo de 2011, radicación n. ${ }^{\circ} 110012204000201101109$ 00, accionante ÓSCAR GUTIÉRREZ SALINAS y accionado Juzgado Dieciocho de Ejecución de Penas y Medidas de Seguridad de Bogotá, con ponencia del Magistrado Alberto Poveda Perdomo:

[...] el hábeas corpus no se puede limitar con requisitos de procedibilidad que el legislador estatutario no estableció, como lo es la exigencia del agotamiento de los recursos dentro del proceso, porque en ese caso se está autorizando la acción solamente a las partes e intervinientes del trámite judicial, únicos facultados para promover recursos o hacer peticiones de libertad, siendo que 
el precepto Supremo concibe la acción, como derecho de acceso a la justicia y garantía de obtener una decisión pronta, a toda persona que advierta la ocurrencia de una captura o privación ilegal de la libertad.

Adicionalmente, la jurisprudencia de las instancias internacionales encargadas de interpretar tratados, constituye un criterio hermenéutico relevante para establecer el sentido de las normas constitucionales sobre derechos fundamentales. Por ejemplo, la jurisprudencia interamericana señala que cuando un Estado es Parte de un tratado internacional como la Convención Americana de Derechos Humanos, todos sus órganos, incluidos sus jueces, también están sometidos a aquél, lo cual les obliga a velar por que los efectos de las disposiciones de la Convención no se vean mermados por la aplicación de normas contrarias a su objeto y fin. Los jueces y órganos vinculados a la administración de justicia en todos los niveles están en la obligación de ejercer ex officio un "control de convencionalidad" entre las normas internas y la Convención Americana, evidentemente en el marco de sus respectivas competencias y de las regulaciones procesales correspondientes. En esta tarea, los jueces y órganos vinculados a la administración de justicia deben tener en cuenta no solamente el tratado, sino también la interpretación que del mismo ha hecho la Corte Interamericana, exégeta último de la Convención Americana.

De acuerdo con lo anterior, en Colombia los jueces están en la obligación de posibilitar que recursos judiciales efectivos a las personas que aleguen ser víctimas de violaciones de derechos humanos, calificación que se debe dar a toda prolongación ilícita de la privación de la libertad (artículo 25), recursos que deben ser sustanciados de conformidad con las reglas del debido proceso legal (artículo 8.1), todo ello dentro de la obligación general, a cargo de los mismos Estados, de garantizar el libre y pleno ejercicio de los derechos reconocidos por la Convención a toda persona que se encuentre bajo su jurisdicción (artículo 1.1). No se debe olvidar que, siguiendo la línea jurisprudencial de la Corte IDH, para que el Estado cumpla lo dispuesto en el artículo 25 de la Convención ADH no basta con que los recursos existan formalmente, sino que es preciso que tengan efectividad en los términos de aquel precepto. Dicha efectividad supone que, además de la existencia formal de los recursos, éstos den resultados o respuestas a las violaciones de derechos reconocidos, ya sea en la Convención, la Constitución o la ley.

El Tribunal ha reiterado que dicha obligación implica que el recurso sea idóneo para combatir la violación y que sea efectiva su aplicación por la autoridad competente. En ese sentido, no pueden considerarse efectivos aquellos recursos que, por las condiciones generales del país o incluso por las circunstancias particulares de un caso dado resulten ilusorios. 
Por lo antes dicho, con atinado apego a los principios pro homine y pro libertate, se ha dicho que no es de recibo esgrimir lisa y llanamente que la acción constitucional es improcedente porque la persona se encuentra privada de la libertad por cuenta de una actuación procesal o que dentro del proceso existen recursos para debatir la situación tildada de lesiva del derecho a la libertad personal. Es necesario que los jueces examinen a profundidad el caso concreto para determinar si se presenta una vía de hecho.

Toda decisión judicial que priva de la libertad debe cumplir unos requisitos formales y sustanciales, de modo que la insatisfacción de tales exigencias deriva en arbitrariedad, supuesto que convierte la decisión judicial en irregular $\mathrm{y}$, con ello, en vía de hecho que autoriza la procedencia del habeas corpus.

En el anotado orden de ideas, no es razonable ni jurídicamente viable que se declare improcedente el habeas corpus cuando las circunstancias particulares del proceso revelan que se profirió una captura ilícita y arbitraria, y permiten inferir que el recurso de reposición no es un mecanismo idóneo para controvertir la legalidad de la captura, la que además deriva de una vía de hecho, y constituye una decisión de trámite o sustanciación, que no puede ser, como ya se dijo, objeto del recurso ordinario (resaltado fuera de texto).

Tal decisión es ejemplo de objetividad y compromiso con el artículo 2 de la Carta Política, que ordena que las autoridades públicas deben hacer efectivo el goce de los derechos, valores y principios constitucionales, alejadas de coyunturas y fenomenologías mediáticas, aplicando, como debe ser, instrumentos internacionales en consonancia con los artículos 93 ibídem y 29 de la Convención Americana sobre Derechos Humanos, lo cual enfatiza los artículos 2 de la Ley 600 de 2000 y 3 de la Ley 906 de 2004.

En fin, basta leer el Informe n. ${ }^{\circ} 35$ de 2007 de la Comisión Interamericana de Derechos Humanos, para entender que nuestra judicatura anda de espaldas a la regulación y entendimiento del Orden Público Internacional de los Derechos Humanos en materia de detención preventiva y privación de la libertad de los sujetos a la acción penal estatal.

\section{EL HABEAS CORPUS COMO MECANISMO EFECTIVO PARA REPARAR LOS DERECHOS CONSTITUCIONALES A LA LIBERTAD VULNERADOS. EL CONTROL DE CONVENCIONALIDAD}

Dado el valor jerárquico de los tratados internacionales, por supuesto respetando siempre la interpretación y aplicación de los mismos a partir de la determinación y escogencia vinculante del mejor estándar de garantías que rija una determinada materia, se ha esbozado un concepto jurídico que cada día toma mayor fuerza, según el 
cual es obligación de toda autoridad de un Estado nacional, pero muy especialmente si la misma tiene la calidad de juez en sentido formal y/o material, de confrontar y contrastar las normas nacionales e internacionales con la finalidad de ejercer un control de convencionalidad ${ }^{25}$ como muestra real, eficaz y eficiente de respeto hacia el valor del Orden Público Internacional de los Derechos Humanos.

En efecto, se ha dicho por la Corte Interamericana de Derechos Humanos que "el poder judicial debe ejercer una especie de control de convencionalidad entre las normas jurídicas internas que aplican en los casos concretos y la Convención Americana sobre Derechos Humanos. En esta tarea el poder judicial debe tener en cuenta no solamente el tratado, sino la interpretación que del mismo ha hecho la Corte Interamericana, intérprete última de la Convención Americana" ${ }^{26}$.

Ese control de convencionalidad es obligatorio, especialmente cuando se alegan mejores garantías a partir del Orden Público Internacional de los Derechos Humanos, toda vez que, como dice el órgano judicial de supervisión antes señalado, "cuando una cuestión ha sido resuelta definitivamente en el orden interno según las cláusulas de la Convención, no es necesaria traerla a esta Corte para su aprobación o confirmación"27.

Así las cosas, la definición de un asunto por parte de los poderes públicos de los Estados nacionales, incluyendo el poder judicial, deben atender el control de convencionalidad so pena de la intervención de los órganos de supervisión internacional sobre Derechos Humanos.

Recientemente ha señalado ${ }^{28}$ :

142. La responsabilidad estatal bajo la Convención solo puede ser exigida a nivel internacional después de que el Estado haya tenido la oportunidad de declarar la violación y reparar el daño ocasionado por sus propios medios. Esto se asienta en el principio de complementariedad (subsidiariedad), que informa transversalmente el Sistema Interamericano de Derechos Humanos, el cual es, tal como lo expresa el Preámbulo de la misma Convención Americana, "coadyuvante o complementario de la [protección] que ofrece el derecho interno de los Estados americanos". De tal manera, el Estado "es el principal

25 Cfr. el Salvamento de Voto del Magistrado NÉstor OsunA PATIÑo a la sentencia de tutela de segunda instancia la Sala Jurisdiccional Disciplinaria del Consejo Superior de la Judicatura caso PETRO, M.P. Pedro Alonso Sanabria Buitrago, radicación n.․ 11001110200020130812001.

26 Corte Interamericana de Derechos Humanos, sentencia de noviembre 24 de 2006, Caso Trabajadores cesados del Congreso vs. Perú, párrafo 128.

27 Corte Interamericana de Derechos Humanos, sentencia de diciembre 6 de 2001, Caso Las Palmeras vs. Colombia, párrafo 33.

28 Corte Interamericana de Derechos Humanos, sentencia de noviembre 30 de 2012, Caso Masacre de Santo Domingo vs. Colombia. 
garante de los derechos humanos de la personas, de manera que, si se produce un acto violatorio de dichos derechos, es el propio Estado quien tiene el deber de resolver el asunto a nivel interno y, [en su caso,] reparar, antes de tener que responder ante instancias internacionales como el Sistema Interamericano, lo cual deriva del carácter subsidiario que reviste el proceso internacional frente a los sistemas nacionales de garantías de los derechos humanos" 29 .

Esas ideas también han adquirido forma en la jurisprudencia reciente bajo la concepción de que todas las autoridades y órganos de un Estado Parte en la Convención tienen la obligación de ejercer un "control de convencionalidad" 30.

Lo anterior significa que se ha instaurado un control dinámico y complementario de las obligaciones convencionales de los Estados de respetar y garantizar los derechos humanos, conjuntamente entre las autoridades internas (primariamente obligadas) y las instancias internacionales (en forma complementaria), de modo que los criterios de decisión puedan ser conformados y adecuados entre sí.

La doctrina especializada afirma que "el fundamento normativo de este control de convencionalidad estaría en el art. 2. ${ }^{\circ}$ de la Convención Americana, de acuerdo con el cual los Estados partes en ese tratado tienen la obligación de armonizar el derecho interno con las disposiciones de esa convención"31.

Resulta obvio tal control puesto que, a nivel convencional, existe la obligatoriedad de instrumentar medidas legislativas y judiciales para hacer efectivos los derechos fundamentales (artículos 2 numeral 2. ${ }^{\circ}$ del Pacto Internacional de Derechos Civiles y Políticos y 2 de la Convención Americana sobre Derechos Humanos).

29 Caso Acevedo Jaramillo y otros vs. Perú. Interpretación de la Sentencia de Excepciones Preliminares, Fondo, Reparaciones y Costas. Sentencia de 24 de noviembre de 2006, párr. 66.

30 Cuando un Estado es Parte de un tratado internacional como la Convención Americana, todos sus órganos, incluidos sus jueces, están sometidos a aquel, lo cual les obliga a velar por que los efectos de las disposiciones de la Convención no se vean mermados por la aplicación de normas contrarias a su objeto y fin, por lo que los jueces y órganos vinculados a la administración de justicia en todos los niveles están en la obligación de ejercer ex oficio un "control de convencionalidad" entre las normas internas y la Convención Americana, evidentemente en el marco de sus respectivas competencias y de las regulaciones procesales correspondientes y en esta tarea, deben tener en cuenta no solamente el tratado, sino también la interpretación que del mismo ha hecho la Corte Interamericana, intérprete última de la Convención Americana. Cfr. Caso Almonacid Arellano y otros vs. Chile. Excepciones Preliminares, Fondo, Reparaciones y costas. Sentencia de 26 de septiembre de 2006. Serie C n. ${ }^{\circ} .154$, párr. 124; Caso Gomes Lund y otros (Guerrilha do Araguaia) vs. Brasil. Excepciones Preliminares, Fondo, Reparaciones y Costas. Sentencia de 24 de noviembre de 2010. Serie C n.․ 219, párr. 176, y Caso Cabrera García y Montiel Flores vs. México. Excepción Preliminar, Fondo, Reparaciones y Costas. Sentencia de 26 de noviembre de 2010. Serie C n. ${ }^{\circ} .220$, párr. 225. Véase asimismo Caso Gelman vs. Uruguay. Fondo y Reparaciones. Sentencia de 24 de febrero de 2011 Serie C n. ${ }^{\circ} .221$, párr. 193.

31 Cfr. ROMERo PÉrez (2011: 63). 
Solo así se garantizan los derechos que emanan del fundamental a la libertad de que dan cuenta los instrumentos convencionales que prevalecen en el orden interno y condicionan la interpretación de derechos y deberes constitucionales de los Estados Partes (artículos 4 y 93 de la Carta Política y 29 de la Convención Americana sobre Derechos Humanos), pues nadie puede ser privado de la libertad física sino conforme a "las causas y condiciones fijadas de antemano" por la Constitución y la ley, pues ello, si no se respeta, deviene en arbitrariedad (numerales $2 .^{\circ}$ y $3 .^{\circ}$ del artículo 7 ibídem y numeral $1 .^{\circ}$ del artículo 9 del Pacto Internacional de Derechos Civiles y Políticos).

Bajo tal perspectiva, no es posible confundir, como está sucediendo frecuentemente en la práctica judicial, el control interno de la actividad judicial que restringe la libertad con el control externo de la misma, no supeditado a aquel, puesto que el primero se funda en los artículos 9 numeral $3 .^{\circ}$ del Pacto Internacional de Derechos Civiles y Políticos y 7 numeral 5..$^{\circ}$ de la Convención Americana sobre Derechos Humanos, y el segundo, por el numeral $4 .^{\circ}$ del artículo 9 del PIDCP y numeral $6 .^{\circ}$ del artículo 7 de la CADH.

Tan es cierto que son dos mecanismos diferentes, no supeditados uno a otro, que el externo no está sujeto al concepto de "sujeto procesal" o "parte" propio de los procedimientos internos, toda vez que el numeral $6 .^{\circ}$ del artículo 7 de la CADH en su última parte dispone que se interpondrán "los recursos por sí o por otra persona", lo que descarta la figura procesal del "sujeto", el cual debe ostentar necesariamente por quien tenga "interés jurídico” (artículo 186 de la Ley 600 de 2000).

No puede ser menos, pues se trata de "un derecho fundamental y, a la vez, una acción constitucional que tutela la libertad personal cuando alguien es privado de la libertad con violación de las garantías constitucionales o legales, o esta se prolongue ilegalmente... y para su decisión se aplicará el principio pro homine" (artículo $1^{\circ}$ Ley 1095 de 2006).

Así entonces, lo imperativo es que se cumpla con lo dispuesto en el artículo 8 de la Ley 1095 de 2006, según el cual "la persona privada de la libertad con violación de las garantías consagradas en la Constitución o en la ley, no podrá ser afectada con medida restrictiva de la libertad mientras no se restauren las garantías quebrantadas. Por tanto, son inexistentes las medidas que tengan por finalidad impedir la libertad del capturado cuando ella se conceda a consecuencia del Hábeas Corpus".

\section{ILEGALIDAD DE LA CAPTURA DERIVADA DE LA INCOMPETENCIA DEL FISCAL PARA ADELANTAR LA INVESTIGACIÓN}

Cuando un fiscal asume una competencia que no le corresponde, para investigar a determinado funcionario, sin que la ley o Constitución lo autoricen, la captura que ordena en el decurso del proceso es manifiestamente ilegal. 
Así resulta evidente, por ejemplo, cuando la captura es ordenada por un fiscal delegado ante la Corte contra un investigado que carece de la condición de aforado, la cual es ilegal, en cuanto proferida por un funcionario que carece de competencia para adelantar la investigación. Es decir que si el investigado no ostenta la calidad de aforado, debe ser adelantada la actuación por un fiscal seccional, a efecto de preservar el debido proceso, el principio de juez natural y el derecho a la doble instancia.

La competencia de los fiscales está determinada por la que les atribuye la ley a los jueces penales ante quienes actúan, y en tal sentido, encuentran limitadas sus atribuciones a la investigación de los delitos concretos que fallarán dichos jueces.

Siendo ello así, y teniendo en cuenta que el artículo 28 de la Constitución indica que "nadie puede ser molestado en su persona o familia, ni reducido a prisión o arresto, ni detenido, ni su domicilio registrado, sino en virtud de mandamiento escrito de autoridad judicial competente", la orden de captura emitida por un fiscal incompetente implica la ilegalidad de la misma.

Si bien el fiscal General de la Nación tiene competencia para designar fiscales especiales para el conocimiento de casos que no son de la competencia funcional de estos, lo que se desplaza es el funcionario, no las funciones, y por tanto, si un fiscal Delegado ante la Corte recibe una asignación especial para investigar un caso cuyo competente es un fiscal Delegado ante Jueces Penales del Circuito, el delegado ante la Corte actuará en dicho proceso en ejercicio de las competencias de fiscal seccional, sin que sea posible transformar o alterar, como consecuencia del desplazamiento, las reglas propias de los procesos de doble instancia.

En tal sentido, si el fiscal es incompetente para asumir la investigación, la captura que ordene será ilegal por defecto orgánico ${ }^{32} \mathrm{y}$, en consecuencia, procederá la acción de habeas corpus, así existan recursos ordinarios para controvertir la legalidad de misma.

32 La jurisprudencia de la Corte Constitucional (sentencias T-231 de 1994, M.P. EdUARDo CifUENTES Muñoz; T-393 de 1994, M.P. Antonio Barrera Carbonell; T-008 de 1998, M.P. Eduardo Cifuentes Muñoz; T-567 de 1998, M.P. Eduardo Cifuentes Muñoz; T-590 de 1999, M.P. Eduardo Cifuentes Muñoz, y T-1180 de 2001, M.P. Marco Gerardo Monroy Cabra), ha elaborado el concepto de vía de hecho para referir aquellas actuaciones judiciales en las que el juez que decide un conflicto jurídico asume una conducta que contraría de manera evidente el ordenamiento vigente violando derechos fundamentales. Tal comportamiento puede traducirse en (1.) la utilización de un poder concedido al juez por el derecho para un fin no previsto en las disposiciones legales (defecto sustantivo), (2.) en el ejercicio de una atribución por un órgano que no es su titular (defecto orgánico), (3.) en la aplicación del derecho sin contar con el apoyo de los hechos determinantes del supuesto legal a partir de pruebas válidas (defecto fáctico), o (4.) en la actuación por fuera del procedimiento establecido (defecto procedimental). Esta carencia sustancial de poder o de desviación del otorgado por la ley, revelan (i.) una manifiesta desconexión entre lo establecido en el ordenamiento y la voluntad del funcionario judicial (que aparejará su descalificación como acto judicial) y (ii.) una clara violación de los derechos fundamentales de quien sufre las consecuencias del acto arbitrario". 


\section{ILEGALIDAD DE LA CAPTURA POR AUSENCIA DE MOTIVACIÓN DE LA ORDEN MISMA SIN SUSPENSIÓN PREVIA DEL SERVIDOR PÚBLICO}

El sentido del artículo 359 del C. de P.P. de 2000, no tiene un objetivo distinto que establecer como presupuesto de legalidad para la captura de servidores públicos la suspensión previa del mismo en el ejercicio del cargo, con el propósito de garantizar intereses y valores constitucionales relevantes, tales como la continuidad y normal desarrollo de la función pública y, al mismo tiempo, la garantía judicial para el procesado, quien solo será capturado una vez su situación administrativa se haya dejado en suspenso mediante un acto administrativo.

Como antes se indicó, la jurisprudencia de la Sala Penal de la Corte Suprema de Justicia ha señalado que la suspensión previa en el ejercicio del cargo constituye un presupuesto para la legalidad de la captura de un servidor público, con la única excepción de la captura de servidores públicos investigados por delitos de conocimiento de los jueces especializados.

En algunos casos, el fiscal podría considerar que la suspensión previa a la captura no es necesaria por cuanto no se afectará con la misma el normal funcionamiento de la administración pública. Sin embargo, si el fiscal no explica las razones por las cuales procede la captura sin suspensión previa, vulnera el principio rector de motivación establecido en el artículo 13 numeral 2 de la Ley 600 de 2000, el cual señala: "El funcionario judicial deberá motivar, incluso cuando se provea por decisión de sustanciación, las medidas que afecten derechos fundamentales de los sujetos procesales".

En otros términos, el artículo 359 numeral 4. ${ }^{\circ}$ de la Ley 600 de 2000 no establece para el fiscal una facultad discrecional que le permita prescindir libremente, en forma arbitraria y sin motivación alguna, de la solicitud de suspensión del servidor público cuya captura va a ordenar, pues en tal caso debe consignar en la respectiva providencia, en consonancia con el referido principio rector, las razones que sustentan el juicio según el cual la captura sin suspensión no afecta el normal funcionamiento de la administración pública.

Así las cosas, cuando pretenda aplicar la norma del art 359 numeral $4 .^{\circ}$ del $\mathrm{C}$, de P.P., el fiscal debe motivar su providencia en este punto, revelando y apreciando las pruebas que sirvan de sustento a su conclusión. Si no lo hace, debe necesariamente concluirse que vulneró las garantías procesales del investigado y colegirse que la captura fue ilegal, porque es consecuencia de una vía de hecho por defecto procedimental, que torna procedente, por tanto, la acción constitucional de habeas corpus ${ }^{33}$.

33 Respecto de la presunta existencia de una vía de hecho sustentada en la constatación de un defecto procedimental, la Corte ha señalado que, "cuando el juez se desvía por completo del 


\section{REFERENCIAS JURISPRUDENCIALES}

\section{Jurisdicción penal}

Corte Suprema de Justicia, Sala de Casación Penal, decisión del 14 de abril de 2010, radicación n. $\left.{ }^{\circ} 33.918\right)$, M.P. YESID RAMÍREZ BASTIDAS.

Corte Suprema de Justicia, Sala de Casación Penal, autos de 26 de junio de 2008, radicación $n .^{\circ} 30.066 ; 10$ de julio de 2008 , radicación $n .^{\circ} 30.156$ y 4 de septiembre de 2009, radicación n. ${ }^{\circ} 32.572$.

Corte Suprema de Justicia, Sala de Casación Penal, auto de 2 de mayo de 2007, radicación $\mathrm{n} .^{\circ} 27.417$, y decisiones de 10 de julio de 2008, radicación n. ${ }^{\circ} 30.156 ; 7$ de noviembre de 2008, radicación n. ${ }^{\circ} 30.772 ; 16$ de enero de 2009, radicación n. ${ }^{\circ}$ 31.066; 21 de abril de 2009, radicación n. ${ }^{\circ} 31.673$ y 4 de septiembre de 2009, radicación n. ${ }^{\circ} 32.572$.

Corte Suprema de Justicia, Sala de Casación Penal, auto del 29 de agosto de 2007, radicación $\mathrm{n} .^{\circ} 28.241$; auto de 25 de enero de 2007, radicación n. ${ }^{\circ} 26.810$; M.P. JAVIER ZAPATA.; auto de 23 de octubre de 2007, radicación n. ${ }^{\circ} 28.598$; decisión de 3 de febrero de 2010, radicación n. ${ }^{\circ} 33.483$, M.P. MARÍA Del Rosario GonZÁlez y decisión del 25 de mayo de 2010, radicación n. ${ }^{\circ}$ 34.246, M.P. SiGIFREDO ESPINOSA.

Corte Suprema de Justicia, Sala de Casación Penal, autos del 26 de junio y 25 de agosto de 2008 , radicaciones n. 30.066 y 30.438 .

Tribunal Superior de Bogotá, Sala Penal, decisión del diecisiete (17) de mayo de dos mil once (2011), radicación n. ${ }^{\circ} 110012204000201101109$ 00. Accionante ÓsCAR GuTIÉRREZ SALINAS, accionado Juzgado Dieciocho de Ejecución de Penas y Medidas de Seguridad de Bogotá, con ponencia del Magistrado doctor AlBerto Poveda Perdomo.

\section{Jurisdicción constitucional}

Corte Constitucional, Sentencia C-296 de 2002, M.P. MARCo Gerardo Monroy CABRA.

Corte Constitucional, Sentencia T-134 de 2004, M.P. JAIME CóRDOBA TRIVIÑo.

procedimiento fijado por la ley para dar trámite a determinadas cuestiones, está actuando en forma arbitraria y con fundamento en su sola voluntad" (Cfr. sentencias T-231 de 1994, M.P. Eduardo Cifuentes Muñoz; T-393 de 1994, M.P. Antonio Barrera Carbonell; T-008 de 1998, M.P. Eduardo Cifuentes Muñoz; T-567 de 1998, m.P. Eduardo Cifuentes MuÑoz; T-590 de 1999, M.P. EduARdo Cifuentes Muñoz, y T-1180 de 2001, M.P. Marco Gerardo Monroy Cabra. 
Corte Constitucional, Sentencia T-231 de 1994, M.P. EduARdo Cifuentes MuÑoz. Reiterada en la Sentencia T-954 de 2006, M.P. RodRIGo EsCOBAR GIL.

Corte Constitucional, Sentencia T-030 de 2005, M.P. JAIME CóRdOBA TriviÑO.

Corte Constitucional, Sentencia T-766 de 2008, M.P. MARCo Gerardo Monroy CABra.

Corte Constitucional, Sentencia C-031 de 1995, M.P. Hernando Herrera Vergara.

Corte Constitucional, Sentencia C-620 de 2001.

Corte Constitucional, Sentencia C-496 de 1994.

Corte Constitucional, sentencias C-301 de 1993 y C-620 de 2001.

Corte Constitucional, Sentencia C-557 de 1992, salvamento de voto de los Magistrados Angarita Barón y Martínez Caballero.

Corte Constitucional, Sentencia C-260 de 1999.

Salvamento de Voto del Magistrado NÉSTOR OsunA PATIÑo a la sentencia de tutela de segunda instancia de la Sala Jurisdiccional Disciplinaria del Consejo Superior de la Judicatura caso Petro, M.P. Pedro Alonso Sanabria Buitrago, radicación n. 11001110200020130812001 .

\section{Tribunales internacionales}

Corte Interamericana de Derechos Humanos, sentencia de noviembre 24 de 2006, Caso "Trabajadores cesados del Congreso vs. Perú".

Corte Interamericana de Derechos Humanos, sentencia de diciembre 6 de 2001, Caso "Las Palmeras vs. Colombia".

Corte Interamericana de Derechos Humanos, sentencia de noviembre 30 de 2012, Caso "Masacre de Santo Domingo vs. Colombia".

Corte Interamericana de Derechos Humanos, sentencia de 24 de noviembre de 2006, Caso “Acevedo Jaramillo y otros vs. Perú”. Interpretación de la Sentencia de Excepciones Preliminares, Fondo, Reparaciones y Costas.

Corte Interamericana de Derechos Humanos, sentencia de 26 de septiembre de 2006, Caso "Almonacid Arellano y otros vs. Chile". Excepciones Preliminares, Fondo, Reparaciones y costas. Serie C n. ${ }^{\circ} 154$, párr. 124; sentencia de 24 de noviembre de 
2010, Caso "Gomes Lund y otros (Guerrilha do Araguaia) vs. Brasil". Excepciones Preliminares, Fondo, Reparaciones y Costas. Serie C n. ${ }^{\circ} 219$; Sentencia de 26 de noviembre de 2010, Caso "Cabrera García y Montiel Flores vs. México". Excepción Preliminar, Fondo, Reparaciones y Costas. Serie C n. ${ }^{\circ} 220$ y sentencia de 24 de febrero de 2011, Caso "Gelman vs. Uruguay". Fondo y Reparaciones. Serie C n. ${ }^{\circ} 221$.

\section{BIBLIOGRAFÍA}

Romero Pérez, Xiomara Lorena (2011). Vinculación de las resoluciones judiciales de la Corte Interamericana. Bogotá: Universidad Externado de Colombia. 